\title{
Is FSI Dependent on Land Availability and Densities? A Comparative Review of FSI in Indian Cities
}

\author{
By G. Karteek
}

\begin{abstract}
In the present era of rapid urbanization, the prime concern is how to regulate development in our cities considering the present growth dynamics. FSI, (Floor space index-the ratio of built-up space on a plot to the area of the plot) is one such regulation predominant in the development control norms, which primarily dictates the overall urban form. In this article, the author investigates the current FSI norms in codes, guidelines and development controls across cities that are classified as large cities. Author takes the secondary data of six cities to find out how FSI is varying in cities with respect to the available land and densities through an empirical analysis. Sample study area building byelaws are taken to make a comparative study on FSI. The result shows FSI in study area are not based on densities or available land but road widths and setbacks and in other cities it varies based on nature of the building activity. Finally, it is found that the FSI is independent of the land availability and density in India and there is no standard model for assigning FSI. To increase or decrease the FSI in a city, shall depend upon some key parameters and an investigation of those parameters shall indicate the FSI control in the cities.
\end{abstract}

Keywords: Floor space index, cities, development controls, density, land.

\section{Introduction}

$\mathrm{FSI}^{1}$ is a common variable in cities and results in varying pattern of development of the urban form and space. FSI is also a tool for planners to control the extent of built-up area on a given plot and also an instrument in the real estate market (Bertaud and Brueckner, 2004). In every city there are development controls, earlier it was informal, now formalized. Post world war-II the concept of FSI came into light from America, also known as FSI in India(Patel B. Shirish 2012). In some large cities classified by the URDPFI draft guidelines 2014 like Delhi, Bangalore, and Kolkata it is known as FAR and in some cities like Mumbai and Chennai it is known as FSI.

Building rules and regulations form a vital link to achieve a city's urban form (Jain 2008). The form of the cities is becoming uncontrollable with pressure of population and urban development. Urban form refers to the pattern of development of the city, considering aspects like density, use of land, transportation, and degree of development. The form of the contemporary city has been perceived as a source of environmental problems. (Alberti et al. 2003;

${ }^{1} \mathrm{FSI}$ is the ratio between total built -up to the plot area available. For convenience FSI term is used in this paper. In India (except for few cities) it is known as Floor Area Ratio (FAR) - The quotient obtained by dividing the total covered area (plinth area) on all floors by the area of the plot (National Building Code, 2005)

Floor area Ratio $($ FAR $)=$ Total covered area of the floors Plot area 
Beatley and Manning 1997; U.S. Environmental Protection Agency EPA 2001; Haughton 1999, 69; Hildebrand 1999; Newman and Kenworthy 1989). City sprawl is further changing the peripheral rural landuse to urban use causing under utilization of urban land (Brueckner 2001).

Urbanization in Indian cities is rapidly increasing. India's population increased to 1.21 billion in 2011 in a decade and the total urban population of India in 2011 is 377.2 million i.e. $31.16 \%$ of its total population. Also it is projected that $70 \%$ net new employment will be generated in cities by 2030. (Mc.Kinsey \& Company, 2010). By 2050, India's urban population will be more than $50 \%$ of its total population. India represents almost $17.31 \%$ of the world's population, which means one out of six people on this planet live in India (Census, 2011). With this exponential growth projection it is credibly important to think on the development intensity permitted in these cities to provide housing and job opportunities. Cities have varying levels of per capita based on the FSI permitted. For example, in Mumbai typical middle-class family occupies 5sqm per capita whereas in Manhattan it is 55sqm per capita (Shirish Patel, 2011).

In recent news, it was revealed that $33 \%$ of Indians occupy living space that is less than that of the prisoners of United States. This was found from the recent National Sample Survey. The data shows that $32 \%$ of the houses are 24 sqm or less making it 5.5 sqm per person. The average size of the Indian house in the urban area was found to be $46.8 \mathrm{sqm}$. i.e. $10.8 \mathrm{sqm}$ per person (NSSO 2007).

\section{Aspects related to FSI in codes and guidelines}

Though the National Building Code 2005 (NBC) mentions general building requirements, it suggests to follow the FSI regulations as mentioned in the Masterplan/zonal plan regulations (NBC 2005). The abutting road is the means of access, which also regulates the height of the building adjacent to the site and shall not be more than 1.5 times the width of road plus the front open space. FSI however of a single storied building is limited in absolute terms by type of construction and occupancy class (NBC 2005) adopted from the American Iron and Steel Institute publication 1961 'Fire protection through modern building codes' mainly considering the fire protection aspect of the buildings. Part 3 of NBC also mentions that the authorities have to modify the FSI for different buildings so as to make them suitable to the cities taking into consideration the density, parking required, road widths and services available. Height restrictions may be decided keeping in view the local fire fighting facilities. Also for Type-1 construction as per NBC Fire and Safety (part-4) the FSI (or FAR) in unlimited considering the maximum permissible height for residential, educational, Institutional, Assembly, business occupancy buildings and other local factors as mentioned above.

URDPFI (Urban and Regional Development Plan Formulation and Implementation) 2014 draft regulations suggest establishing mixed-use zone and encouragement of Transit oriented development by unlocking land values as high FSI in the influence zone of transit corridors within the planning framework to encourage public transport systems. Also URPDFI 2014 suggests land based financing resources such as development charges, pricing of floor space above a certain limit, conversion charges, impact fees, etc. Also, to encourage transit-oriented development it suggests compact neighborhoods for shorter commutes by promoting higher FSI in influence zone of transit corridors. URDPFI also suggests ways to generate financial resources from vacant land, unauthorized informal development, pricing of higher FSI and unutilized FSI. Many cities have also used the concept of TDR (Transfer of Development Rights). TDR is a technique, which allows using part of the development potential of a land to be used in another local within the defined zones in the form of additional FSI.

In the 12th five-year plan (2012-2017 volume 2 pg.330); there is a mention of FSI in Indian cities being low as compared to many other cities in the world. This also results in the low per capita 
space available. Densification through higher FSI will make compact and efficient cities accommodating more people and pricing the higher FSI will generate resources for funding urban infrastructure projects. In some cities, FSI vary by location and land use density zones are typically small identified by street width and capacity as well as land use patterns. For example, Singapore makes effective use of FSI variations by location and type of use. The transport nodes have higher FSI, where development fees and tradable development rights can be further used, as it needs higher infrastructure investments. The plan also stresses that optimizing infrastructure and density are key elements in rationalizing the same.

National Urban Transport policy (NUTP), 2006 suggests integration of land use and transport planning as one of the objectives to combat urban sprawl and loss of high quality agricultural land and open space.

\section{Land disposition in Indian cities}

Land disposition of six Indian cities show that the land available in the corporation limit is the maximum in the city of Delhi with an extent of 1397 sq. $\mathrm{km}$. and the population density is the highest in the corporation limits of Mumbai having a density of 24,822 persons per sq.km. with $480 \mathrm{sq} . \mathrm{km}$. extent of land available in the corporations limits. Also the FSI values in Mumbai are the least compared to some of the major cities in India. In Mumbai, the FSI values are very low compared to other major cities in the world. The values are uniform over large areas, not differentiated between commercial and residential, around train stations and not linked to the land market values.

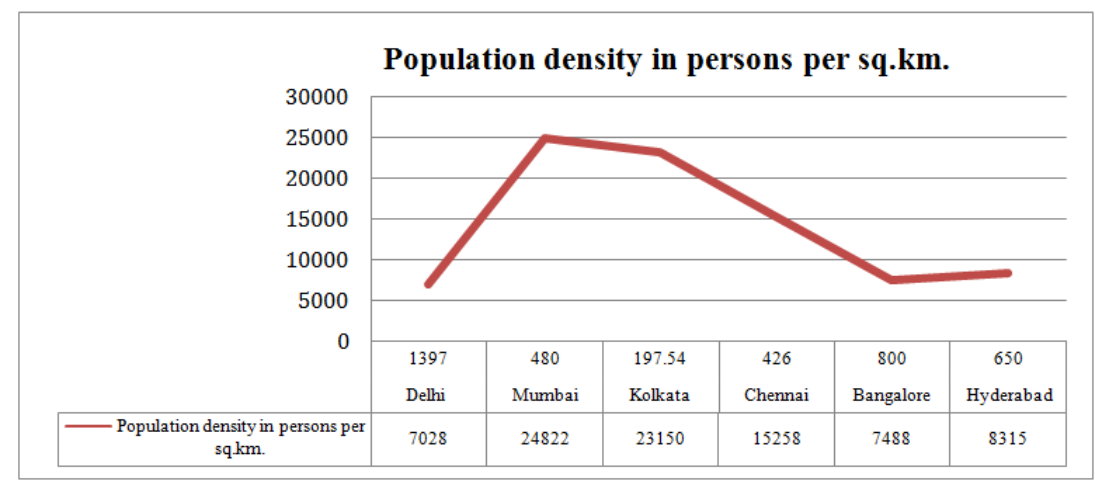

Figure 1 Area Vs. population density in Indian cities Source: Municipal Corporation websites and City Development Plan of the above cities

Table 1

\begin{tabular}{|l|c|c|c|c|c|c|}
\hline City & Delhi & Mumbai & Kolkata & Chennai & Bangalore & Hyderabad \\
\hline $\begin{array}{l}\text { Maximum permissible FSI in } \\
\text { commercial areas }\end{array}$ & 2.25 & $1.33^{*}$ & 4 & 2.5 & 2.5 & $\begin{array}{c}\text { No FSI } \\
\text { specified }\end{array}$ \\
\hline $\begin{array}{l}\text { Maximum permissible FSI in residential } \\
\text { areas }\end{array}$ & 3.5 & $1.33^{*}$ & 3.2 & 2.5 & 2.5 & $\begin{array}{c}\text { No FSI } \\
\text { specified }\end{array}$ \\
\hline
\end{tabular}

*Uniform in the Island city, higher FSI allowed for redevelopment

Source: Masterplan and Development control regulations document of various city authorities

The above table 1 explains the variation in FSI in the Indian cities and reveals that even with high population densities Indian cities have a control on FSI. In Mumbai the first set of development 
control regulations were formulated in 1964 under the Bombay Town Planning Act 1955. Highest FSI of 4.5 was prescribed for the Nariman point reclamation considering high cost of land and construction including piling in the reclaimed land (Annez Patricia et al 2010) but later reduced to 1.33. Also the $C R Z^{2}$ in Mumbai further reduce the supply of the land available for Mumbai (Alain Bertaud, 2011). In the new draft development plan 2034, Development control regulations, Greater Mumbai, it is mentioned that the objective of the chapter on FSI is to facilitate redevelopment of built-up plots, efficient use of land considering existing and proposed public transport network and increasing the per-capita space both for living and working. The permissible FSI has been worked out in terms of the base FSI, Transfer of Development Rights and premium FSI. Premium FSI is on payment of premium on $70 \%$ of ready reckoner rate of land and $100 \%$ of ready reckoner rate for land upto a maximum of 2.5 (Draft Development Plan, Greater Mumbai-2034, 2014).

Higher FSI in some of the cities is allowed in the suburbs where the supply of infrastructure in not full fledged. Government regulations sometimes control the development explicitly like for example in Lutyens zone-New Delhi, FSI increase is not permitted and on the other side Shahjahanabad-the old city area has the highest density in Delhi where tradable FSI is given to owners who surrender land for public facilities or for conserving heritage values considering parking, accessibility and fire hazard (MPD, 2021). This led to higher densities in the fringe areas of Delhi making it an inverted compact city (Ashok Kumar, 2004), which also resulted in the increase of the average trip length as the geographical area increased more than three times.

\section{FSI variation in others cities of the world}

The FSI values in Indian cities are very low compared to other major cities in the world including Mumbai, which has one of the highest densities comparable to that of New York. Alain Bertuad (2011) concluded that most cities in the world have high FSI in the CBD except for Mumbai where FSI is higher in Bandra Kurla area. In Hongkong increase in FSI actually helped to resolve the per capita space. The FSI of the government housing was 3 during the 1970's and later it was increased to about 5 in the 1980's which resulted in an increase in per capita space from $3.2 \mathrm{sqm}$. to $5 \mathrm{sqm}$. (Sullivan and Chen, 1997;Ng and Wong, 2004). Even in Shanghai, the average floor space per person increased from $3.6 \mathrm{sqm}$. in 1984 to $34 \mathrm{sqm}$. per person by allowing higher FSI for in-situ redevelopment of obsolete buildings in the corporation areas (Alain Bertaud, 2011). In many large cities FSI ranges 15 near CBD's to 1 in the suburbs but unlike in India it varies from 1 to 4 maximum.

Seoul city spatial structure is compact; expansion is restricted by hills and northern border. It is a polycentric city with large CBD and many subcentres connected with a transport grid like metro system. Built up population density in the built-up area is similar to Mumbai. In Seoul the FSI in CBD ranges from 8 to 10, 0.5 to 4 in residential areas and higher FSI in and around areas of transit nodes. In Newyork, the FSI ranges from 15 in the CBD to 0.6 in the suburbs. As India is a developing country one could argue the increase in FSI cannot be supported by the existing infrastructure. Kala Seetharam Sridhar (2007) mentions that if there is a proportionate increase in the increase in built up in response to increase in FSI than there is a need to augment the infrastructure where FSI increase is projected. Low FSI has lead to increase in land prices and rental values. Low FSI in Mumbai had resulted in 4.9 sq.m. of extremely low residential floor space per person (Bertaud 2011). Bertaud (2011) also stresses that an increase in FSI has two purposes; first, it allows for more household space without relocation and second, it decreases the

2 CRZ-Coastal regulation zone. The Ministry of Environment and Forests, India had issued CRZ notification in 1991 under the Environment Protection Act 1986 to provide comprehensive measures for protection and conservation of the coastal environments (Ministry of Environment and Forests, 2011). 
urban sprawl.

\section{Factors affecting FSI norms}

In Delhi, the FSI norms are clearly mentioned as per the type of building activity indicating the maximum coverage and the parking standards. For residential plots in Delhi the FSI decreases as the plot size increases. Some of the cities have adopted transit-oriented development for sites within the influence zone of a transit node. Delhi encourages higher FSI and height along $500 \mathrm{~m}$ on both sides from the centre line of MRTS/major transport corridor earmarked as influence zone, in the form of redevelopment of planned areas (MPD, 2021). Delhi also promotes redevelopment strategies in a minimum area of 4 hectares with enhanced FSI subject to a maximum of 4 , is allowed for planned and unplanned areas through a process of reorganization and optimum utilization of land.

In Bangalore, the FSI regulations for residential and commercial plots vary as per the abutting road width but are independent of the plot sizes. Only variable FSI and ground coverage as per the site/plot area are stipulated for group housing, semi detached houses, row houses, factories, industrial buildings, IT and BT related categories. Bangalore city has also adopted transit-oriented development regulations for plots abutting $60 \mathrm{~m}$ or more road width within $150 \mathrm{~m}$ radius of any transit hub giving an additional FSI of 0.5 over and above the FSI provided for the said use of plot on payment of fees. The FSI variation is given as per the road widths for residential, commercial and public semi-public, traffic and transportation, public utility building categories that vary from 1.5 to 2.5. There is no difference in FSI variation in residential and commercial plots based on the road widths (Zoning regulations, BMRDA Bangalore, 2031).

In Hyderabad, the regulations are common for all types of buildings unlike few other cities in India like New Delhi, Chennai, Kolkata and Bangalore, which vary by type of building activity like commercial, residential, industrial etc. and there is no limit for high rise buildings abutting the roads wider than $30 \mathrm{~m}$. In Chennai the FSI norms are specified considering the building activity on a certain plot and the FSI permissible in the category remains constant irrespective of the plot size. In Chennai, for multi-storied buildings the FSI allowed is maximum 2.5 for 1500 sqm. site area and reduces for plots of more than 2500 sqm to only 2.0 .

\section{FSI norms for residential plots}

New Delhi regulates the residential plot FSI with respect to the area of the plot and stipulates the number of dwelling units on the plot. Larger is the size of the plot, density increases but the FSI reduces to 1.2 from 3.5 on the smallest plot. Delhi has ground coverage and setback regulations as per the plot sizes apart from the above, considering a maximum height of $15 \mathrm{~m}$ in all plots. In Chennai, plot level FSI remains constant at 1.5 and only the numbers of dwelling units vary from 6 to 9. In Mumbai, the FSI were uniform over large areas as stated above as identified by the local authority and irrespective of the building activity and the plot sizes. In Bangalore, width of the road specified the FSI for residential and commercial plots. The wider the road, the higher is the FSI in case of Bangalore. This is unlike Hyderabad (Andhra Pradesh and Telangana) where the FSI3 achieved, was found to be increasing with the increase in plot size. The presently followed building regulations create inappropriate FSI patterns. For analyzing the FSI patterns, sample plot areas were taken into consideration as mentioned in table 2.

${ }^{3}$ FSI component was removed from the Andhra Pradesh building regulations in 2006. Maximum height and setbacks are stipulated as per the abutting road width for the plot sizes. 
Table 2

\begin{tabular}{|c|c|c|c|c|}
\hline \multicolumn{3}{|c|}{ ASSUMPIONS } & $\begin{array}{c}\text { Considering maximum Height } \\
\text { permissible as per the G.O.168, } \\
\text { Andhra Pradesh (2012) }\end{array}$ \\
\hline $\begin{array}{c}\text { Plot size category in sqm. as } \\
\text { per G.O. }\end{array}$ & $\begin{array}{c}\text { Plot size taken in } \\
\text { sqm. }\end{array}$ & $\begin{array}{c}\text { Plot } \\
\text { dimensions }\end{array}$ & \\
\hline & & Width & Length & 10 (3floors) \\
\hline $50-100$ & 80 & 8 & 10 & 10 (3floors) \\
\hline $100-200$ & 150 & 10 & 15 & 10 (3floors) \\
\hline $200-300$ & 240 & 12 & 20 & 12 (4floors) \\
\hline $300-400$ & 375 & 15 & 25 & 12 (4floors) \\
\hline $400-500$ & 475 & 19 & 25 & 15 (5floors) \\
\hline $500-750$ & 600 & 20 & 30 & 15 (5floors) \\
\hline $750-1000$ & 900 & 25 & 36 & 18 (6floors) \\
\hline $1000-1500$ & 1200 & 30 & 40 & 18 (6floors) \\
\hline $1500-2500$ & 2400 & 40 & 60 & 18 (6floors) \\
\hline Above 2500 & 2600 & 40 & 65 & 18 (6floors) \\
\hline Above 2500 & 3000 & 50 & 60 & \\
\hline & & & & \\
\hline & & &
\end{tabular}

The FSI pattern was calculated based on the setbacks stipulated in each of the plot categories along abutting road width of $12 \mathrm{~m}$ and above $30 \mathrm{~m}$. Interestingly, it was also found that the FSI values achieved on minimum road width of $12 \mathrm{~m}$ was higher than the FSI achievable on the maximum road width of $30 \mathrm{~m}$ and beyond for the same plot size as shown in the figure.

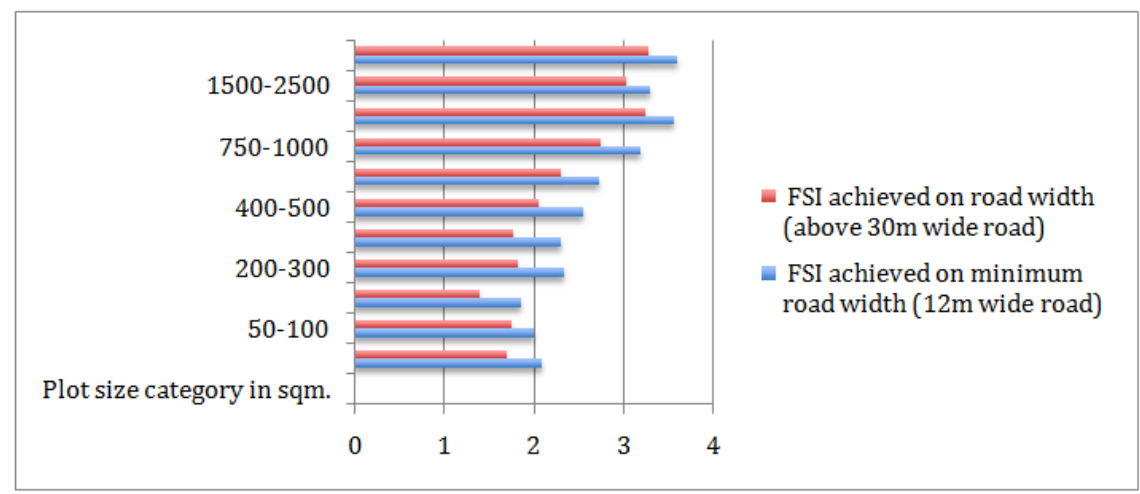

Figure 2 Comparison of FSI values achieved on varying road widths in Vijayawada (Source: Author)

\section{FSI norms for group housing}

In Hyderabad, the regulations allow group housing in sites more than $4000 \mathrm{sqm}$. in area without slab on FSI permitting taller buildings. In Bangalore, the regulations allow for Group housing for plots more than 1 hectare or $10,000 \mathrm{sqm}$ in area with an FSI of 1.5 allowing maximum $60 \%$ ground coverage and upto 2.25 for sites more than 30,000 sqm. with 40\% maximum ground coverage. In Delhi, it is allowed for plots with minimum $3000 \mathrm{sqm}$. area with a maximum FSI of 2 irrespective of the site area beyond the specified minimum area. It regulates densities as per the dwelling unit sizes- upto $40 \mathrm{sqm} .500 \mathrm{DU} / \mathrm{Ha}, 40 \mathrm{sqm}$ to $80 \mathrm{sqm}$. $250 \mathrm{DU} / \mathrm{Ha}$ and above $80 \mathrm{sqm} .175 \mathrm{DU} / \mathrm{Ha}$. 
Table 3 GROUP HOUSING FSI norms in Indian cities

\begin{tabular}{|l|c|c|c|c|c|c|c|}
\hline \multirow{2}{*}{ City } & $\begin{array}{c}\text { Plot size } \\
\text { taken in sqm. }\end{array}$ & \multicolumn{2}{|c|}{ Plot dimensions } & $\begin{array}{c}\text { Maximum } \\
\text { Ground } \\
\text { coverage }\end{array}$ & $\begin{array}{c}\text { Ground } \\
\text { coverage }\end{array}$ & $\begin{array}{c}\text { FSI for Group } \\
\text { housing in } \\
\text { Indian cities }\end{array}$ & $\begin{array}{c}\text { Total } \\
\text { built up } \\
\text { achieved }\end{array}$ \\
\hline Bangalore & 10000 & 100 & 100 & $60 \%$ & 6000 & 1.5 & 15000 \\
\hline New Delhi & 10000 & 50 & 200 & $33.30 \%$ & 3330 & 2 & 20000 \\
\hline Chennai & 10000 & 50 & 200 & - & - & 1.5 & 15000 \\
\hline Hyderabad & 10000 & 50 & 200 & - & - & $4.02 *$ & 40176 \\
\hline
\end{tabular}

* FSI achieved considering the site area, setbacks and $10 \%$ open space to be left as per the bye laws

The comparison of FSI permitted in-group housing schemes in cities reveal that in Hyderabad housing project, assuming a site area of 10,000 sqm. yields the maximum FSI as compared to other cities though the city has comparatively low density than Mumbai and Kolkata and also the city is lacking serious infrastructure crunch. This will lead to more supply as the builders and developers will try to build the maximum as evident in the peri-urban area of Hyderabad along the outer ring road. In most cases FSI is less when the area of the plot/site is higher unlike Hyderabad.

\section{Results and Conclusion}

The above study shows that there is considerable variation of components considered for FSI and shows that FSI is not based on available land or densities but road widths and setbacks and in other cities it is based on nature of the building activity. In Andhra Pradesh the maximum builtup area allowed on a plot is irrespective of the nature of activity in a given plot, which is actually a means to simplify the regulations but not an attempt to consider the parameters that are essential to understand the variation in the pattern of development. As there is no standard model for assigning FSI, it is imperative to consider some important parameters, which affect the increase or decrease of the FSI to regulate the growth of the city. The next stage of the research is to establish the key parameters that influence the FSI norms and create a better choice of living.

\section{References}

Annez, P. C., Bertaud, A., Patel, B., Phatak, V. K., Annez, P. C., \& World Bank. (2010). Working with the market: A new approach to reducing urban slums in India. Washington, D.C: The World Bank.

Bertaud Alain (2011). Mumbai FAR/FSI Conundrum, Retrieved from http://alain-bertaud.com (Accessed on January 20, 2014)

Bureau of Indian Standards (2005). National Building Code of India part 3, Development Control rules and General Building requirements, Part 3

Chennai Metropolitan Development Authority (May 2013). Second Masterplan for Chennai Metropolitan Area 2026, Development regulations Volume II

Delhi Urban Arts Commission and Delhi Development Authority (2014), Unified Building Byelaws for Delhi 2014

Density Architecture (2013). A Study on high density residential architectures, Wordpress (Online) Retrieved from http://densityarchitecture.wordpress.com/

Government of Andhra Pradesh (April 07, 2012). Government Order Ms. No. 168, Andhra Pradesh Building rules, 2012 Retrieved from http;//goir.ap.gov.in/

Government of India (2011), Census of India

Government of Karnataka (2013). Masterplan for Neelamangala Local Planning area, 2031 (2013), Zoning regulations Government of West Bengal (Februrary 14, 2007), The West Bengal Municipal (Building) rules, 2007

Jabareen, Y. (January 01, 2007). Sustainable urban forms: Their typologies, models, and concepts. Sage Urban Studies Abstracts, 35, 3, 38 .

Jenks, M., \& Burgess, R. (2003). Compact cities: Sustainable urban forms for developing countries. London: Spon. 
Kala, S. S. (January 01, 2010). Impact of Land Use Regulations: Evidence from India's Cities. Urban Studies, 47, 7, 1541-1569.

Ministry of Urban Development (February 2014), Urban and Regional Development Plans Formulation and Implementation Guidelines, Draft Volume I

Neuman Micheal, (2005). The Compact city Fallacy, Journal of Planning Education and Research 25: 11-26

Patel B. Shirish (2011). Analyzing urban layouts-Can high density be acbieved with good living conditions ?, Environment and Urbanization 23: 583

Rogers Richard, 1997. Cities for a small Planet, Icon editions, Westview Press

Shirgaokar Manish 2013, Limitations of Anti-Floors space Index position, Economic and Political Weekly Vol XLVIII No.29

Times of India, Hyderabad, 2014 Floor space index norm likely for high rises, Retrieved from http://timesofindia.indiatimes.com/floor-space-index-norm-likely-for-high rises/articleshow/20320421.cms (Accessed on January 24, 2014) 